\title{
Mothers' attitude to the use of a combined oral contraceptive pill by their daughters for menstrual disorders or contraception
}

\author{
KW Yiu, Symphorosa SC Chan *, Tony KH Chung
}

\section{A B S T R A C T}

Introduction: Mothers' attitude may affect use of combined oral contraceptive pills by their daughters. We explored Chinese mothers' knowledge of and attitudes towards the use of combined oral contraceptive pills by their daughters for menstrual disorders or contraception, and evaluate the factors affecting their attitude.

Methods: This survey was conducted from October 2012 to March 2013, and recruited Chinese women who attended a gynaecology clinic or accompanied their daughter to a gynaecology clinic, and who had one or more daughters aged 10 to 18 years. They completed a 41-item questionnaire to assess their knowledge of and attitude towards use of the combined oral contraceptive pills by their daughters. The demographic data of the mothers and their personal experience in using the pills were also collected.

Results: A total of 300 women with a mean age of 45.2 (standard deviation, 5.0) years completed the questionnaire. Only $58.3 \%$ of women reported that they had knowledge about the combined oral contraceptive pills; among them, a majority (63.3\%) reported that their source of knowledge came from medical professionals. Of a total possible score of

This article was published on $24 \mathrm{Feb}$ 2017 at www.hkmj.org.
22, their mean knowledge score for risk, side-effects, benefits, and contra-indications to use of combined oral contraceptive pills was only 5.0 (standard deviation, 4.7). If the medical recommendation to use an oral contraceptive was to manage their daughter's dysmenorrhoea, menorrhagia, acne, or contraception needs, $32.0 \%, 39.3 \%, 21.0 \%$ and $29.7 \%$, respectively would accept this advice. Women who were an ever-user of combined oral contraceptive pills or who were more knowledgeable about combined oral contraceptives had a higher acceptance rate.

Conclusions: Chinese women had a low acceptance level of using combined oral contraceptive pills as a legitimate treatment for their daughters. This was associated with lack of knowledge or a high degree of uncertainty about their risks and benefits. It is important that health caregivers provide up-to-date information about combined oral contraceptive pills to women and their daughters.

\section{Hong Kong Med J 2017;23:150-7}

DOI: $10.12809 / \mathrm{hkmj} 164993$

KW Yiu, MRCOG, FHKAM (Obstetrics and Gynaecology)

SSC Chan *, FRCOG, FHKAM (Obstetrics and Gynaecology)

TKH Chung, FRANZCOG, FRCOG

Department of Obstetrics and Gynaecology, The Chinese University of Hong Kong, Prince of Wales Hospital, Shatin, Hong Kong

* Corresponding author: symphorosa@cuhk.edu.hk

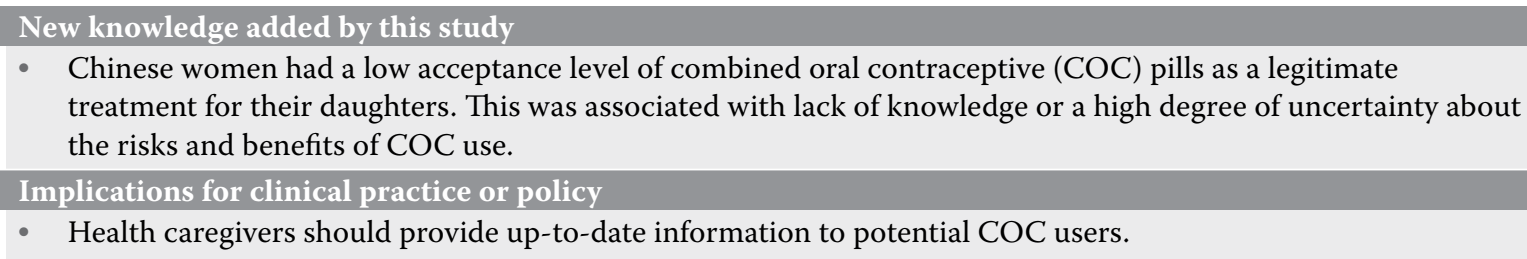

\section{Introduction}

The combined oral contraceptive (COC) pill is an effective contraception. It has a very low-risk profile documented over several decades and its protective effect on endometrial and ovarian carcinoma has been well established. ${ }^{1}$ It is also an effective treatment for menstrual problems and polycystic ovarian syndrome, ${ }^{2,3}$ which are common in adolescents. ${ }^{4-7}$ The prevalences of menorrhagia, dysmenorrhoea, and menstrual symptoms in adolescent girls have been reported to be $17.9 \%, 68.7 \%$, and $37.7 \%$, respectively. ${ }^{4}$ The prevalence of polycystic ovarian syndrome in adolescent girls has been reported to be $16 \%$ in those who attended a local paediatric and adolescent gynaecology clinic. ${ }^{5}$ Nonetheless, the use of COC pills in Chinese women has remained low; only $1 \%$ of women of reproductive age (20-49 years) in China used the pills in $2010 .^{8}$ There are some obstacles to access although family planning is a relatively well-funded area of health care in China 
and has been implemented for decades. In Hong Kong, the situation is slightly less unusual. From an online survey conducted in Hong Kong, 12.6\% of women had used an oral contraceptive in the year prior to the survey, but many of them had stopped using it. ${ }^{9}$ According to the annual report of the Family Planning Association of Hong Kong in 2014$2015,22 \%$ of the 48363 clients who practised birth control, including women who were both married and unmarried, used an oral contraceptive. ${ }^{10}$ Only $6 \%$ of teenage girls who attended the youth health care centres used COC pills for contraception. ${ }^{11}$

Although sex education has been integrated into the primary and secondary educational curriculum for many years, efforts to provide quality sex education have been limited. ${ }^{12}$ According to a survey conducted by the Hong Kong SAR Government, sex education at the junior secondary school level is limited to an average of 3 to 4 school hours only. ${ }^{13}$ Sometimes concepts emphasised included protection of self and avoidance of sex, especially prior to marriage. ${ }^{14}$ The median age of marriage in Hong Kong is now close to 30 years. It is notable that Hong Kong has a high rate of therapeutic abortion that is underestimated by official statistics because an indeterminate proportion is performed in mainland China due to cost considerations. In women attending for their antenatal visit, a high proportion of $36.5 \%$ reported a previous therapeutic abortion (unpublished data from our institute). This suggests that women of reproductive age may not have been educated about contraception. There is little published information on the use of COC pills for the management of menstrual problems in Hong Kong but it is likely to be low. Misconceptions and myths about COC pills are likely to be the main obstacles to use. Although extensive high-quality information about use of COC is currently available from various sources, many women remain unaware of the non-contraceptive benefits of COC. They also have little awareness of the risks of $\mathrm{COC} .{ }^{15}$ For female adolescents, their decision about whether to use COC is likely to be influenced by their parents, especially their mothers, who may be giving advice to their daughters based on little or erroneous knowledge. This may lead mothers to make decisions that are not in their daughter's best interests.

Focused education about COC may lead to a more balanced view, both in adolescents and their mothers. In a study of Korean and Japanese university students, significant correlation between knowledge of and positive attitude towards COC pills was reported. ${ }^{16}$ Mothers in Asia are also often involved in their teenage daughters' decision to begin sexual relationships, the use of contraceptives, and even vaccination. ${ }^{17,18}$ Since the mothers' attitude may affect use of COC by their daughters, we explored Chinese mothers' knowledge of and attitudes towards such

\section{母親對於女兒使用複合口服避孕藥作為治理 月經失調或避孕的態度 \\ 姚嘉樺、陳丞智、鍾國衡}

引言：母親的態度很可能影響女兒對複合口服避孕藥的使用。我們探 討了華藉婦女對複合口服避孕藥的認識, 以及她們對於女兒使用這些 避孕藥作為治理月經失調或避孕的態度, 並評估影響她們態度的因 素。

方法：本研究調查邀請了2012年10月至2013年3月期間自己或陪同女 兒到婦科門診求診, 並有一個或以上年齡介乎 10 至 18 歲女兒的女性。 受訪者須填寫問卷乙份。問卷上共41項問題評估受訪者對複合口服避 孕藥的認識以及對於女兒使用這些避孕藥的態度; 收集受訪者的基本 數據和她們個人使用複合口服避孕藥的經驗。

結果：是項調查共收到 300 份完成的問卷。受訪者平均年齡 45.2 歲 （標準差， 5.0歲）。只有 $58.3 \%$ 的受訪者填寫自己對複合口服避孕藥 有認識；當中大多數（63.3\%）的資料來源都是醫護人員。問卷的最 高分數為 22 分, 受訪者對於複合口服避孕藥的平均「知識得分」（即 包括對其風險、副作用、好處和使用的禁忌症的理解）卻只有5.0分 （標準差，4.7分）。假如女兒出現不同的婦科症狀，有 $32.0 \%$ 受訪者 接受因經痛、39.3\%因月經過多、21.0\%因痤瘡和 $29.7 \%$ 因避孕而接受 醫學建議讓女兒服食口服避孕藥。自己曾服食複合口服避孕藥或對這 種藥有認識的受訪者, 對口服避孕藥的接受程度較高。

結論：華籍婦女對於使用複合口服避孕藥治療女兒的接受程度較低。 這與她們對這種藥物缺乏認識或者不理解其風險和相關好處有關。重 要的是, 醫護人員應為女性及她們的女兒提供有關複合口服避孕藥的 最新知識。

use. Mothers' knowledge about the COC pills and factors affecting their attitude were also evaluated.

\section{Methods}

The study was conducted from October 2012 to March 2013 in the gynaecology clinic of a tertiary teaching hospital in Hong Kong. Women who attended the clinic or accompanied a daughter to the clinic, and who had one or more daughters aged 10 to 18 years were recruited. Women who did not speak or read Chinese were excluded. The participants completed a 41-item questionnaire to assess their knowledge of and attitude towards use of COC pills by their daughters. Firstly, they were asked to self-assess their own knowledge of the COC pill. The knowledge domain consisted of 19 items testing their knowledge of the non-contraceptive health benefits and side-effects of COC pills, and three items on contra-indications to use of $\mathrm{COC}$ pills. For each item, participants were asked to respond "yes", "no", or "don't know". They were then asked about their attitudes to the use of COC pills by their daughters aged 10 to 18 years for the management of dysmenorrhoea, menorrhagia, acne, or as a contraceptive. They were asked to respond from "strongly agree", "agree", "disagree", to "strongly disagree". Reasons for agreeing or disagreeing with 
the use of COC pills and the appropriate age or life-events for using COC pills by their daughters were also asked. Finally, demographic data and their personal experience in using COC pills were collected. Knowledge score and uncertainty score were calculated for the participants based on their response $\mathrm{s}^{15,16}$-knowledge score was defined as the score of correct answers with 1 score given for each correct answer (ie range from 0-22); a "don't know" reply would create the uncertainty score. The participants provided written informed consent, and approval was obtained from the local ethics committee (CRE-2012.186).

\section{Statistical analyses}

Descriptive statistics were used to summarise participants' demographic information. Association between participant characteristics and overall attitude was explored using Chi squared and independent-samples $t$ test. A P value of $<0.05$ was considered statistically significant. All statistical analyses were conducted using the SPSS (Windows version 18.0; SPSS Inc, Chicago [IL], United States). Assuming that $50 \%$ of the women accepted the use of COC pills by their daughters with an accepted error of $0.05 \%, 278$ women were required. An additional $10 \%$ was recruited to prepare for an incomplete questionnaire.

\section{Results}

Apart from 150 women who were excluded because they did not have a daughter aged 10 to 18 years, a total of 317 women were invited to participate; 302 agreed and 300 (94.6\%) completed the questionnaire. Demographic characteristics of the participants are shown in Table 1 . Their mean age was 45.2 years (range, 28-58 years). The median number of daughters was one and most participants $(88.3 \%)$ were married. Most (>70\%) had high school education. In all, 125 (41.7\%) were ever-users of COC pills, including both current and ex-users. Overall, 175 (58.3\%) reported that they had knowledge about the COC pills, while 125 (41.7\%) reported no knowledge.

The rates of giving correct answers about the COC pill and the comparison between ever- and never-users of COC pills are shown in Table 2. Of a total possible score of 22 , the mean $( \pm$ standard deviation) knowledge score of all the participants was $5.0 \pm 4.7$. Of all the participants, only approximately $20 \%$ of the mothers correctly answered that COC pills would not cause carcinoma of ovary and corpus; $26.0 \%, 29.7 \%$, and $30.3 \%$ respectively correctly answered that COC pills did not have proven teratogenicity, cause pelvic inflammatory disease and infertility; $10.3 \%$ knew that COC pills would not cause weight gain and $25.7 \%$ answered that COC pills would not lead to a depressive mood.
TABLE I. Demographics of the participants

\begin{tabular}{lc}
\hline Demographics & No. (\%) of participants ${ }^{*}+$ \\
\hline Mean \pm SD (range) age (years) & $45.2 \pm 5.0(28-58)$ \\
\hline No. of daughters & $166(55.3)$ \\
\hline 2 & $134(44.7)$ \\
Marital status & \\
\hline Single & $8(2.7)$ \\
\hline Married & $265(88.3)$ \\
\hline Divorced & $16(5.3)$ \\
\hline Widowed & $10(3.3)$ \\
Cohabited & $1(0.3)$ \\
\hline Education level & $175(58.3)$ \\
\hline Primary school & $190(63.3)$ \\
\hline High school & $32(10.7)$ \\
\hline Tertiary or above & $7(2.3)$ \\
\hline Missing data & \\
\hline Ever-user of CoC pills & $125(41.7)$ \\
\hline Yes & $175)$ \\
\hline No & \\
\hline
\end{tabular}

Abbreviations: $\mathrm{COC}=$ combined oral contraceptive; $\mathrm{SD}=$ standard deviation

* Unless otherwise indicated

+ Because of rounding, not all percentages total 100

In all, $43.3 \%, 33.0 \%$, and $25.3 \%$ knew that COC pills had the benefits of regulating the menstrual cycle, decreasing menstrual flow, and helping to relieve dysmenorrhoea, respectively. Moreover only $20 \%$ knew that the COC pills are not contra-indicated in people with a family history of breast cancer but is contra-indicated in thromboembolism. The knowledge score of the 175 women who responded to have knowledge of the COC pills was significantly higher than those who reported lack of knowledge $(8.0 \pm 4.4$ vs $3.0 \pm 3.7 ; \mathrm{P}<0.001)$. Among those who declared they had knowledge about the use of COC pills, their sources of knowledge were from medical professional (63.3\%), media (30.3\%), friends (24.6\%), family members (6.9\%), school (2.9\%), and others (1\%).

The rate of responding "uncertain" to the health benefit, side-effects, or contra-indications of COC use ranged from $43.7 \%$ to $71.0 \%$ for each item. The mean uncertainty score among all participants was $13.0 \pm 7.6$. The uncertainty score was significantly higher in participants who reported to have lack of knowledge when compared with those reported to have knowledge about COC pills $(15.6 \pm 7.1$ vs $9.1 \pm$ 6.7; $\mathrm{P}<0.001)$.

Among the ever-users, 43 (34\%), five (4\%), and 96 (77\%) women reported that COC pills had been used to manage their own menstrual problems, acne 
TABLE 2. Rates of giving correct answers about COC and comparison between ever- and never-users of COC pills

\begin{tabular}{|c|c|c|c|c|}
\hline & \multicolumn{3}{|c|}{ No. (\%) of participants who gave correct answer } & \multirow[t]{2}{*}{ P value* } \\
\hline & $\begin{array}{l}\text { Whole group } \\
(n=300)\end{array}$ & $\begin{array}{c}\text { COC ever-user } \\
(n=125)\end{array}$ & $\begin{array}{c}\text { COC never-user } \\
(n=175)\end{array}$ & \\
\hline \multicolumn{5}{|c|}{ COC would not increase the risk of the following conditions } \\
\hline Carcinoma of the ovary & $64(21.3)$ & $39(31.2)$ & $25(14.3)$ & $<0.005$ \\
\hline Carcinoma of the corpus & $65(21.7)$ & $42(33.6)$ & $23(13.1)$ & $<0.005$ \\
\hline Infertility & $91(30.3)$ & $60(48.0)$ & $31(17.7)$ & $<0.005$ \\
\hline Teratogenicity & $78(26.0)$ & $54(43.2)$ & $24(13.7)$ & $<0.005$ \\
\hline Pelvic inflammatory disease & $89(29.7)$ & $55(44.0)$ & $34(19.4)$ & $<0.005$ \\
\hline Weight gain & $31(10.3)$ & $20(16.0)$ & $11(6.3)$ & 0.006 \\
\hline Depressive mood & $77(25.7)$ & $48(38.4)$ & $29(16.6)$ & $<0.005$ \\
\hline Hirsutism & $94(31.3)$ & $63(50.4)$ & $31(17.7)$ & $<0.005$ \\
\hline Acne & $103(34.3)$ & $69(55.2)$ & $34(19.4)$ & $<0.005$ \\
\hline Osteoporosis & $60(20.0)$ & $36(28.8)$ & $24(13.7)$ & $<0.005$ \\
\hline \multicolumn{5}{|c|}{$\mathrm{COC}$ would increase the risk of the following conditions } \\
\hline Carcinoma of the breast & $44(14.7)$ & 27 (21.6) & $17(9.7)$ & 0.004 \\
\hline Water retention & $89(29.7)$ & $50(40.0)$ & $39(22.3)$ & 0.001 \\
\hline Increase appetite & $78(26.0)$ & $51(40.8)$ & $27(15.4)$ & $<0.005$ \\
\hline Sexually transmitted infections & $12(4.0)$ & $6(4.8)$ & $6(3.4)$ & 0.550 \\
\hline \multicolumn{5}{|l|}{ COC pills have the following benefits } \\
\hline Regulate the menstrual cycle & $130(43.3)$ & $76(60.8)$ & $54(30.9)$ & $<0.005$ \\
\hline Reduce menstrual flow & $99(33.0)$ & $59(47.2)$ & $40(22.9)$ & $<0.005$ \\
\hline Relieve dysmenorrhoea & $76(25.3)$ & $47(37.6)$ & $29(16.6)$ & $<0.005$ \\
\hline Treatment for acnes & $69(23.0)$ & $47(37.6)$ & $22(12.6)$ & $<0.005$ \\
\hline Treatment for hirsutism & $20(6.7)$ & $12(9.6)$ & $8(4.6)$ & 0.085 \\
\hline \multicolumn{5}{|c|}{$\mathrm{COC}$ is contra-indicated for the following conditions } \\
\hline History of thromboembolism† & $57(19.0)$ & $35(28.0)$ & $22(12.6)$ & 0.001 \\
\hline Family history of breast cancer $\ddagger$ & $62(20.7)$ & $33(26.4)$ & $29(16.6)$ & 0.038 \\
\hline Smoker (age $<35$ years) $\ddagger$ & 89 (29.7) & $50(40.0)$ & 39 (22.3) & 0.001 \\
\hline
\end{tabular}

Abbreviation: $\mathrm{COC}=$ combined oral contraceptive

* Comparison is made between ever- and never-users of COC

+ It is a contra-indication to COC use

$\neq$ It is not a contra-indication to COC use

problems, and as contraception, respectively. Table 3 lists the participants' acceptance rate of $\mathrm{COC}$ use by their daughters in different gynaecological conditions and the comparison between ever- and never-users of COC pills. More ever-users than never-users accepted the use of COC for their daughter's gynaecological indications. Participants who accepted their daughter's use of COC also had a higher knowledge score and lower uncertainty score (Table 4). Table 5 shows the participants' reasons for accepting use of $\mathrm{COC}$ pills by their daughters. Recommendation by medical professionals was the major reason, followed by the knowledge that $\mathrm{COC}$ pills provided effective contraception.

Age, education level, and whether they had previous experience of side-effects of $\mathrm{COC}$ pills were not associated with participants' acceptance of $\mathrm{COC}$ use by their daughters. Among the 125 ever-users of COC pills, 65 (52.0\%) reported they had experienced side-effects, including weight gain $(n=45)$, fluid retention $(n=25)$, headache $(n=12)$, increase in appetite $(n=8)$, mode disturbance $(n=8)$, and acne $(n=4)$. Table 6 lists the reasons for disagreement with the use of COC pills by their daughters for menstrual problems. Finally, only 71 (23.6\%) participants thought that the use of COC pills was appropriate in girls aged 12 to 18 years.

\section{Discussion}

Our study highlights a notable lack of knowledge 
TABLE 3. Participants' acceptance of COC use by their daughters for different gynaecological conditions and comparison between ever- and never-users of COC pills

\begin{tabular}{|c|c|c|c|c|}
\hline & \multicolumn{3}{|c|}{ No. (\%) of participants } & \multirow[t]{2}{*}{ P value* } \\
\hline & Whole group $(n=300)$ & COC ever-user $(n=125)$ & COC never-user $(n=175)$ & \\
\hline Menorrhagia & 118 (39.3) & $63(50.4)$ & $55(31.4)$ & 0.001 \\
\hline Dysmenorrhoea & $96(32.0)$ & $48(38.4)$ & $48(27.4)$ & 0.045 \\
\hline Acne & $63(21.0)$ & $32(25.6)$ & $31(17.7)$ & 0.098 \\
\hline Contraception & $89(29.7)$ & $49(39.2)$ & $40(22.9)$ & 0.002 \\
\hline
\end{tabular}

Abbreviation: $\mathrm{COC}=$ combined oral contraceptive

* Comparison is made between ever- and never-users of COC

TABLE 4. Comparison of the knowledge score and uncertainty score in participants who agreed or disagreed with the use of COC pills by their daughters under different gynaecological conditions

\begin{tabular}{|c|c|c|c|c|c|}
\hline & & Knowledge score* & $P$ value & Uncertainty score* & P value \\
\hline \multirow[t]{2}{*}{ Menorrhagia } & Agree & $5.94 \pm 4.96$ & 0.029 & $11.72 \pm 7.47$ & 0.055 \\
\hline & Disagree & $4.63 \pm 4.54$ & - & $13.48 \pm 7.69$ & - \\
\hline \multirow[t]{2}{*}{ Dysmenorrhoea } & Agree & $6.55 \pm 4.87$ & $<0.001$ & $10.60 \pm 7.37$ & $<0.001$ \\
\hline & Disagree & $4.08 \pm 4.35$ & - & $14.35 \pm 7.51$ & - \\
\hline \multirow[t]{2}{*}{ Acne } & Agree & $7.02 \pm 5.09$ & 0.001 & $10.48 \pm 7.62$ & 0.006 \\
\hline & Disagree & $4.53 \pm 4.47$ & - & $13.56 \pm 7.55$ & - \\
\hline \multirow[t]{2}{*}{ Contraception } & Agree & $6.66 \pm 4.74$ & $<0.001$ & $10.06 \pm 7.54$ & 0.001 \\
\hline & Disagree & $4.37 \pm 4.54$ & - & $14.12 \pm 7.39$ & - \\
\hline
\end{tabular}

Abbreviation: $\mathrm{COC}=$ combined oral contraceptive

* Data are shown in mean \pm standard deviation

TABLE 5. Participants' reasons for accepting use of COC pills by their daughters for menstrual problems*

\begin{tabular}{lc}
\hline Reason & No. (\%) \\
\hline Recommended by medical professionals & $120(40.0)$ \\
COC is an effective form of contraception & $38(12.7)$ \\
$\begin{array}{l}\text { COC is an effective treatment for } \\
\text { menstrual problems }\end{array}$ & $31(10.3)$ \\
Side-effects are tolerable & $24(8.0)$ \\
Easy to use & $21(7.0)$ \\
Knowledgeable to COC & $14(4.7)$ \\
Recommended by friends/family & $7(2.3)$ \\
\hline
\end{tabular}

Abbreviation: $\mathrm{COC}=$ combined oral contraceptive

* Some participants did not answer this question and for those who answered, they could give more than one reason

about the use of COC pills in many Hong Kong Chinese mothers. Many were uncertain or had erroneous beliefs about the use of COC pills. They believed that such usage would lead to cancers, fetal deformity, and cause infertility and pelvic inflammatory disease. These misconceptions and uncertainties may further reinforce their non- acceptance of the COC pills as an appropriate medication for their daughters. This inevitably often leads to suboptimal treatment for their daughters.

Fear of increased risk of cancer is an important reason for low acceptance of COC pills and only $22 \%$ of our participants thought it did not increase the risk for carcinoma of ovary or uterus. More than $60 \%$ of the participants were uncertain about the risk of cancer with the use of COC pills (results not shown). Research has shown that contraceptives have a significantly protective effect on carcinoma of ovary and corpus uteri. ${ }^{19,20}$ In fact, a collaborative reanalysis of individual data from 53297 women with breast cancer and 100239 women without breast cancer from 54 epidemiological studies revealed that while women were taking $\mathrm{COC}$ pills and in the 10 years after stopping, there was a small increase in the relative risk of breast cancer. ${ }^{21}$ There was, however, no significant excess risk of having breast cancer diagnosed $\geq 10$ years after stopping use of COC pills. The breast cancer incidence rises steeply with age. The estimated excess number of cancers diagnosed in the period between starting use and 10 years after stopping increases with age at last use. The estimated excess number of breast cancers diagnosed up to 10 years after stopping use from the age of 16 to 19 years among 10000 women has been reported to be 0.5 
TABLE 6. Participants' reasons for disagreement with the use of COC pills by their daughters for menstrual problems

\begin{tabular}{|c|c|}
\hline Reason & No. $(\%)^{\star}$ of participants \\
\hline Self-assessed poor knowledge on COC pills & $144(48.0)$ \\
\hline Worry about its side-effects of weight gain and water retention & $135(45.0)$ \\
\hline Worry about its long-term side-effects like infertility, carcinogenicity, and teratogenicity & $113(37.7)$ \\
\hline Their daughters are young & $97(32.3)$ \\
\hline Menstrual problems are common in adolescence and observation is preferred & $79(26.3)$ \\
\hline Alternative methods are available for treatment of menstrual problems & $72(24.0)$ \\
\hline $\mathrm{COC}$ is a synthetic hormone & $50(16.7)$ \\
\hline COC would affect breast development & $44(14.7)$ \\
\hline Use of COC would increase the likelihood of their daughters to have coitus & $40(13.3)$ \\
\hline Use of COC would increase the likelihood of their daughters to have multiple sexual partners & $40(13.3)$ \\
\hline Use of COC would increase the likelihood of their daughters to have premarital sex & $37(12.3)$ \\
\hline Others might stigmatise their daughters as being sexually active if their daughters use COC & $34(11.3)$ \\
\hline COC compliance is difficult & $16(5.3)$ \\
\hline $\mathrm{COC}$ is an ineffective treatment form & $15(5.0)$ \\
\hline Spouse objection & $11(3.7)$ \\
\hline
\end{tabular}

Abbreviation: $\mathrm{COC}=$ combined oral contraceptive

* Participants could give more than one reason

(95\% confidence interval, 0.3-0.7) only. ${ }^{21}$ The Nurses' Health Study with 121701 participants followed up for 36 years revealed that longer duration of COC use was strongly associated with premature mortality due to breast cancer. ${ }^{22}$ Another highlight was that only $20.7 \%$ of our participants knew that a family history of breast cancer was not a contraindication to use of COC pills.

Another common misconception is that the use of COC pills can lead to future subfertility. The COC pill preserves fertility by diminishing the risk of ectopic pregnancy. ${ }^{23}$ According to a review, 1-year pregnancy rates after discontinuation of COC ranged from $79 \%$ to $96 \%$, similar to those reported following discontinuation of barrier methods or no contraception. ${ }^{24}$ Moreover, the progestogen effect of COC pills results in production of thick, tenacious cervical mucus that resists penetration by bacteria and spermatozoa and reduces the risk of upper genital tract infection. Use of COC pills was also quoted to be protective against symptomatic pelvic inflammatory disease, with a $50 \%$ reduction in rate of hospitalisation for the disease, with itself being a risk factor for subfertility. ${ }^{25}$ The COC pill does not protect against sexually transmitted infections. On the other hand, there is no evidence to support the notion that the use of COC pills is associated with high-risk sexual behaviour in adolescents, which is a very common fear among Hong Kong mothers.

Primary dysmenorrhoea is prevalent during adolescence. Approximately $6.4 \%$ of adolescents or
$29 \%$ of those reporting severe dysmenorrhoea seek help from a physician. ${ }^{4}$ A review and meta-analysis of five trials of the use of COC pills concluded that it was more effective than placebo in managing dysmenorrhoea. ${ }^{2}$ One of the most common problems reported by adolescents is irregular and/or profuse menstruation. The COC pill is also effective in treating and preventing heavy menstrual bleeding. In our study, only $25 \%$ to $43 \%$ of the participants knew that it is an appropriate treatment for menstrual problems and $50 \%$ were uncertain.

The fear of side-effects often leads to reluctance to using new treatments. ${ }^{18}$ In many cases, such fears are often unfounded. In our study, participants believed that weight gain and depressive mood were side-effects of COC pills, although pooled analysis of a placebo-controlled trial showed no difference in weight gain. ${ }^{26}$ Furthermore, depressive symptoms are common in adolescence. ${ }^{27}$ In a randomised controlled study, there was no difference in mood changes throughout the menstrual cycle between COC users and non-users. ${ }^{28}$ In a prospective study of 43 adolescents, subjects anticipated more sideeffects than they actually experienced after 6 months of taking COC pills. ${ }^{29}$

It is important to provide correct information to women and their teenage daughters if they are contemplating the use of COC pills. In our study, $40 \%$ of participants indicated that recommendation from a medical professional was a critical factor in their acceptance of the use of COC pills by their 
daughters.

Only $19 \%$ of participants were aware that thromboembolism is a contra-indication to $\mathrm{COC}$ use. Venous thromboembolism in Asians has been reported to be low. ${ }^{30} \mathrm{~A}$ recent case-control study confirmed that current exposure to any $\mathrm{COC}$ poses a 3-times higher risk of venous thromboembolism compared with no exposure in the previous year. ${ }^{31}$ The risk is higher with $\mathrm{COC}$ pills containing desogestrel (odds ratio, 4.3), gestodene (3.6), drospirenone (4.1), and cyproterone (4.3) than the second-generation $\mathrm{COC}$ pills with levonorgestrel (2.4) and norgestimate (2.5). ${ }^{31}$ The risk of venous thromboembolism is also increased for COC users with a family history of venous thromboembolism. ${ }^{32}$ Clinicians should assess the woman's personal and family history of thromboembolism, and provide information about the warning symptoms of venous thromboembolism before prescribing a new generation pill. As recommended by the World Health Organization, the COC pill is not contraindicated in smokers $<35$ years old ${ }^{33}$; approximately $30 \%$ of our participants answered this correctly.

This study has several limitations. First, there may be selection bias as subjects were women who presented to the gynaecology clinic or accompanied their daughter to a gynaecology clinic for a gynaecological problem. The results may not be generalised to the whole population of Hong Kong. Second, the questionnaire was not validated and the questions did not include all aspects of the use of COC pills. Third, we relied on women's self-reported use of COC pills and could not verify the information. Despite these, the questionnaire included the most widely studied aspects of non-contraceptive benefits and risks of the COC pill and knowledge score or uncertainty score have been used in previous literature. ${ }^{15,16}$ Although this study was conducted in only one centre and in Chinese women only, it helps clinicians to understand the low levels of acceptance of and compliance with prescribed COC pills.

The degree of misconception among Hong Kong mothers about COC use is of concern. Hong Kong has a well-developed education system with many highly regarded universities. The reported limited sex education in schools may be responsible for this knowledge gap of Hong Kong mothers. ${ }^{13}$ This may in turn have an impact on the advice they give their daughters, who are usually compliant with their mother's wishes. Specific training in communication and counselling skills should be provided to health care professionals when promoting sexual health to women and adolescents. ${ }^{34}$

\section{Conclusions}

Our study found that the Hong Kong Chinese women who attended a gynaecology clinic of a tertiary centre had a low acceptance rate of the use of COC pills by their daughters. This low acceptance was associated with a lack of knowledge and misconception of the risks and benefits of the $\mathrm{COC}$ pills. Such ignorance will exert an adverse influence on the choice of treatment for many gynaecological problems in teenage daughters.

\section{Declaration}

All authors have disclosed no conflicts of interest.

\section{References}

1. Vessey M, Painter R. Oral contraceptive use and cancer. Findings in a large cohort study, 1968-2004. Br J Cancer 2006;95:385-9.

2. Proctor ML, Roberts H, Farquhar CM. Combined oral contraceptive pill (OCP) as treatment for primary dysmenorrhoea. Cochrane Database Syst Rev 2001;(4):CD002120.

3. Nader S, Diamanti-Kandarakis E. Polycystic ovary syndrome, oral contraceptives and metabolic issues: new perspectives and a unifying hypothesis. Hum Reprod 2007;22:317-22.

4. Chan SS, Yiu KW, Yuen PM, Sahota DS, Chung TK. Menstrual problems and health-seeking behaviour in Hong Kong Chinese girls. Hong Kong Med J 2009;15:1823.

5. Chung PW, Chan SS, Yiu KW, Lao TT, Chung TK. Menstrual disorders in a Paediatric and Adolescent Gynaecology Clinic: patient presentations and longitudinal outcomes. Hong Kong Med J 2011;17:391-7.

6. Esmaelizadeh S, Delavar MA, Amiri M, Khafri S, Pasha NG. Polycystic ovary syndrome in Iranian adolescents. Int J Adolesc Med Health 2014;26:559-65.

7. Christensen SB, Black MH, Smith N, et al. Prevalence of polycystic ovary syndrome in adolescents. Fertil Steril 2013;100:470-7.

8. Wang C. Trends in contraceptive use and determinants of choice in China: 1980-2010. Contraception 2012;85:570-9.

9. Lo SS, Fan SY. Acceptability of the combined oral contraceptive pill among Hong Kong women. Hong Kong Med J 2016;22:231-6.

10. The Family Planning Association of Hong Kong. 20142015 Annual report. Available from: http://www. famplan.org.hk/fpahk/en/template1.asp?style=template1. asp\&content=about/annualreport.asp. Accessed $28 \mathrm{Apr}$ 2016.

11. The Family Planning Association of Hong Kong. Youth sexuality in Hong Kong secondary school survey. Available from: http://www.famplan.org.hk/fpahk/en/template1. asp?content=info/research.asp. Accessed 28 Apr 2016.

12. Che FS. A study of the implementation of sex education in Hong Kong secondary schools. Sex Educ 2005;5:281-94.

13. Survey of life skills-based education on HIV/AIDS at junior level of secondary schools in Hong Kong. Red Ribbon Centre, Department of Health, Hong Kong SAR Government; 2014.

14. Wong WC, Lee A, Tsang KK, Lynn H. The impact of AIDS/ sex education by schools or family doctors on Hong Kong Chinese adolescents. Psychol Health Med 2006;11:108-16.

15 . Voqt C, Schaefer M. Disparities in knowledge and interest about benefits and risks of combined oral contraceptives. Eur J Contracept Reprod Health Care 2011;16:183-93. 
16. Lim HJ, Lee MS, Cho YH, Kazumi U. A comparative study of knowledge about and attitudes toward the combined oral contraceptives among Korean and Japanese university students. Pharmacoepidemiol Drug Saf 2004;13:741-7.

17. Bachar R, Yogev Y, Fisher M, Geva A, Blumberg G, Kaplan B. Attitudes of mothers toward their daughters' use of contraceptives in Israel. Contraception 2002;66:117-20.

18. Chan SS, Cheung TH, Lo WK, Chung TK. Women's attitudes on human papillomavirus vaccination to their daughters. J Adolesc Health 2007;41:204-7.

19. Cibula D, Gompel A, Mueck AO, et al. Hormonal contraception and risk of cancer. Hum Reprod Update 2010;16:631-50.

20. Bitzer J. Oral contraceptives in adolescent women. Best Pract Res Clin Endocrinol Metab 2013;27:77-89.

21. Collaborative Group on Hormonal Factors in Breast Cancer. Breast cancer and hormonal contraceptives: collaborative reanalysis of individual data on 53297 women with breast cancer and 100239 women without breast cancer from 54 epidemiological studies. Lancet 1996;347:1713-27.

22. Charlton BM, Rich-Edwards JW, Colditz GA, et al. Oral contraceptive use and mortality after 36 years of follow-up in the Nurses' Health Study: prospective cohort study. BMJ 2014;349:g6356.

23. Burkman R, Schlesselman JJ, Zieman M. Safety concerns and health benefits associated with oral contraception. Am J Obstet Gynecol 2004;190 (4 Suppl):S5-22.

24. Mansour D, Gemzell-Dianielsson K, Inki P, Jensen JT. Fertility after discontinuation of contraception: a comprehensive review of the literature. Contraception 2011;84:465-77.

25. Guillebaud J, MacGregor A. Contraception: your questions answered. 6th ed. London: Churchill Livingstone; 2013.
26. Gallo MF, Lopez LM, Grimes DA, Carayon F, Schulz KF, Helmerhorst FM. Combination contraceptives: effects on weight. Cochrane Database Syst Rev 2014;(1):CD003987.

27. Saluja G, Iachan R, Scheidt PC, Overpeck MD, Sun W, Giedd JN. Prevalence of and risk factors for depressive symptoms among young adolescents. Arch Pediatr Adolesc Med 2004;158:760-5.

28. Walker A, Bancroft J. Relationship between premenstrual symptoms and oral contraceptive use: a controlled study. Psychosom Med 1990;52:86-96.

29. Rosenthal SL, Cotton S, Ready JN, Potter LS, Succop PA. Adolescents' attitudes and experiences regarding levonorgestrel $100 \mathrm{mcg} /$ ethinyl estradiol $20 \mathrm{mcg}$. J Pediatr Adolesc Gynecol 2002;15:301-5.

30. Lee WS, Kim KI, Lee HJ, Kyung HS, Seo SS. The incidence of pulmonary embolism and deep vein thrombosis after knee arthroplasty in Asians remains low: a meta-analysis. Clin Orthop Relat Res 2013;471:1523-32.

31. Vinogradova Y, Coupland C, Hippisley-Cox J. Use of combined oral contraceptives and risk of venous thromboembolism: nested case-control studies using the QResearch and CPRD databases. BMJ 2015;350:h2135.

32. Zöller B, Ohlsson H, Sundquist J, Sundquist K. Family history of venous thromboembolism is a risk factor for venous thromboembolism in combined oral contraceptive users: a nationwide case-control study. Thromb J 2015;13:34.

33. Medical eligibility criteria for contraceptive use. 5th ed. Geneva: World Health Organization; 2015.

34. Yip BH, Sheng XT, Chan VW, Wong LH, Lee SW, Abraham AA. 'Let's talk about sex'-a knowledge, attitudes and practice study among paediatric nurses about teen sexual health in Hong Kong. J Clin Nurs 2015;24:2591-600. 